\title{
Pancreatic duodenal homeobox-1, PDX-1, a major regulator of beta cell identity and function
}

\author{
C. M. McKinnon, K. Docherty \\ Department of Molecular and Cell Biology, University of Aberdeen, Institute of Medical Sciences, Foresterhill, Aberdeen, UK
}

\begin{abstract}
Pancreatic duodenal homeobox -1 is a transcription factor that is expressed in beta and $\delta$ cells of the islets of Langerhans and in dispersed endocrine cells of the duodenum. It is involved in regulating the expression of a number of key beta-cell genes as well as somatostatin. It also plays a pivotal part in the development of the pancreas and islet cell ontogeny. Thus homozygous disruption of the gene in mice and humans results in pancreatic agenesis. Heterozygous mutations in the gene result in impaired glucose tolerance and symptoms of diabetes as seen in MODY4 and late-onset Type II (non-insulin-dependent) diabetes mellitus. In adults pancreatic duodenal homeobox-1 expression is increased in duct cells of the pancreas
\end{abstract}

that have been induced to proliferate and differentiate to form new islets. Defects in pancreatic duodenal homeobox-1 could therefore contribute to Type II diabetes by affecting compensatory mechanisms that increase the rate of beta-cell neogenesis to meet the increased insulin secretory demand. It could also be a pharmacological target for beta-cell defects in Type II diabetes, while its role as a regulator of islet stem cell activity is being exploited to produce a replenishable source of islet tissue for transplantation in Type I (insulin-dependent) diabetes mellitus. [Diabetologia (2001) 44: 1203-1214]

Keywords Insulin gene, islets of Langerhans, transcription, gene expression, diabetes mellitus.
Pancreatic duodenal homeobox-1 (PDX-1) originally appeared in the literature under several guises, namely IUF-1, IPF-1, IDX-1, STF-1 and GSF. It was discovered independently by a number of laboratories working on the regulation of hormone gene expression and development in the islets of Langerhans and in the developmental biology of the frog. The early studies on the insulin gene promoter, which were predominantly on the rat insulin I gene, led to mapping two major regulatory sequences of the re-

Received: 2 May 2001 and in revised form: 7 June 2001

Corresponding author: Dr. K. Docherty, Department of Molecular and Cell Biology, University of Aberdeen, Institute of Medical Sciences, Foresterhill, Aberdeen, AB25 2ZD, UK, e-mail: k.docherty@aberdeen.ac.uk

Abbreviations: MODY, Maturity onset diabetes of the young; PDX-1, pancreatic duodenal homeobox-1; PI 3-kinase, phosphatidylinositol 3-kinase gions -104 to -112 and -233 to -241 [1]. Termed initially the IEB1 and IEB2 boxes but now known as the E1 and E2 boxes [2], these sequences bound a single protein, IEF1, that was expressed specifically in beta cells [3]. IEF1 was found to be a heterodimer comprising two basic helix loop helix (bHLH) proteins, E47 and NeuroD1 also known as BETA2 [4, 5]. E47, one of two splice products of the $E 2 A$ gene, has a widespread distribution whereas NeuroD1 is restricted to neuroendocrine cells. Mutagenesis of the E boxes completely abolished the activity of the insulin promoter.

Subsequently a beta cell-specific factor, named IUF-1, was identified by electrophoretic mobility shift assay (EMSA). It bound to three sites located between -77 and $-84,-210$ and -217 , and -313 and -320 in the human insulin gene promoter [6]. Termed the CT boxes, and now known as the A boxes [2], one of these sites (the CT2 box) was closely related to a 
site in the rat insulin I promoter $(-210$ to -221$)$ that showed no activity by itself but which potentiated the activity of the adjacent E2 (IEB2) sequence [7]. The consensus binding site for IUF-1, 5, $\mathrm{C}(\mathrm{C} /$ T)CTAATG, was mapped by methylation interference analysis [6] and DNase footprinting [8]. SouthWestern analysis indicated that IUF-1 DNA binding activity could be separated by gel filtration chromatography into two proteins of $\mathrm{Mr} 46 \mathrm{~K}$ and $115 \mathrm{~K}$ [9].

At the same time a beta cell-specific factor, IPF-1, was shown to bind to a related consensus sequence $5^{\prime} \mathrm{CC}(\mathrm{C} / \mathrm{T}) \mathrm{TAATGG}$ at -70 to -85 in the rat insulin I promoter [10]. Another study [11] cloned an IPF-1 cDNA that encoded a protein of 283 amino acids with a calculated $\mathrm{M}_{\mathrm{r}}$ of $31 \mathrm{~K}$. The deduced amino acid sequence showed a homeodomain that diverged from the Antennapedia prototype, containing a unique histidine at position 45 of helix 3 . It was also noted that the homeodomain was identical to the previously published partial homeodomain sequence of the XIHox 8 protein from Xenopus laevis [12].

Simultaneously, two other groups by screening cDNA libraries prepared from somatostatin-expressing islet cell lines cloned homeodomain-encoding cDNAs that were termed STF-1 [13] and IDX-1 [14]. The subsequent cloning of a cDNA encoding IUF-1 [15] and a glucose sensitive beta cell-specific transcription factor (GSF) [16, 17] showed that IPF-1, STF-1, IDX-1, IUF-1 and GSF were similar proteins and that XIHox 8 was a Xenopus homologue [18]. Due to this plethora of names for the same factor, there was much confusion until the gene was renamed pancreatic duodenal homeobox $-1(p d x-1)$ by the international Committee on Standardised Genetic Nomenclature for Mice. While the Human Genome Database Nomenclature Committee designated ipf- 1 as the name for the human gene. In this review we will use the convention ipf-1 for the human gene and PDX-1 for all species forms of the protein.

\section{Distribution and structure of PDX-1}

PDX-1 expression is limited to beta cells and some somatostatin-expressing cells of the islets of Langerhans. It is also expressed in dispersed endocrine cells of the duodenum, and in the developing brain [19].

PDX-1 contains 283 amino acids with a predicted molecular weight of $31 \mathrm{~K}$. Like most other transcription factors, PDX-1 possesses a modular structure with separate functional domains (Fig.1). It contains within the middle region an antennapedia-like homeodomain flanked on both sides by proline-rich regions. The homeodomain is involved in DNA binding and protein-to-protein interactions. A highly conserved histidine residue at position 189 that is unique to the homeodomain of PDX-1 and a KIWFQN motif that lies in helix 3 of the homeodomain are partic-

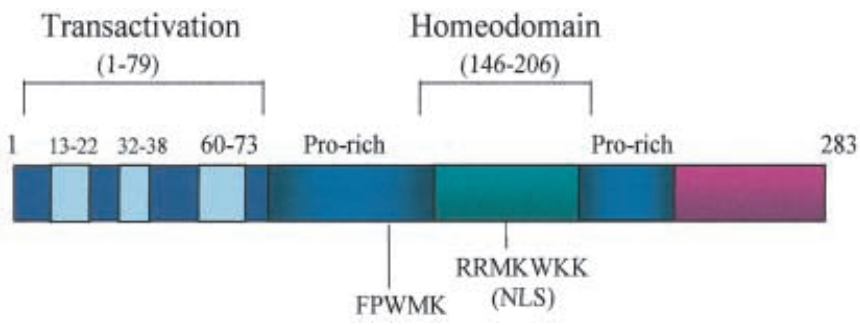

Fig. 1. Structure of PDX-1. Schematic representation of the predicted structure of PDX-1 showing the antennapedia-like homeodomain flanked by two proline rich regions. The $\mathrm{NH}_{2}-$ terminal activation domain comprising three sub-domains is also indicated as are a basic residue-rich nuclear localisation signal (NLS) within helix three of the homeodomain and a pentapeptide motif that interacts with $\mathrm{PBX}$ located close to the homeodomain. Sequences COOH-terminal to the homeodomain (amino acids 144-283) could also have transactivation properties [20]

ularly important in DNA binding [20]. A proline enriched transactivation domain is located within the $\mathrm{NH}_{2}$-terminal region and can be divided into three evolutionarily conserved subdomains [20,21].

The coding region of the human ipf-1 gene contains two exons separated by an intervening sequence [22]. Exon I encodes the $\mathrm{NH}_{2}$-terminal transactivation domain and part of the homeodomain while exon 2 encodes the remaining portion of the homeodomain and the $\mathrm{COOH}$-terminal region of the protein (Fig. 2). The human ipf-1 gene is located on chromosome 13q12 (12.1) $[22,23]$, the mouse $p d x-1$ gene (which also contains two exons) on the distal end of chromosome 5 [24] and the rat $p d x$ - 1 gene on chromosome 12 [25]. The primary sequence is highly conserved between zebrafish [26], Xenopus and mammals.

\section{PDX-1 and the regulation of gene expression}

Several lines of evidence including co-transfection of reporter constructs harbouring promoter sequences containing putative PDX-1 DNA binding sites along with PDX-1, and detailed mapping of PDX-1 DNA binding sites by electrophoretic mobility assay indicate that PDX-1 regulates a number of genes involved in maintaining beta-cell identity and function. These include insulin [11], glucose transporter 2 (GLUT-2) [27], glucokinase [28] and islet amyloid polypeptide [29-31]. It also regulates somatostatin gene expression in islet $\delta$ cells [13] and in the developing brain [32]. The arrangement of PDX-1 binding sites in the upstream regulatory regions of these genes is shown in Figure 3. It could even autoregulate its own expression [33].

The ability of PDX-1 to activate gene transcription in a tissue specific manner is dependent on its capacity to interact with other transcription factors. This is 
A.

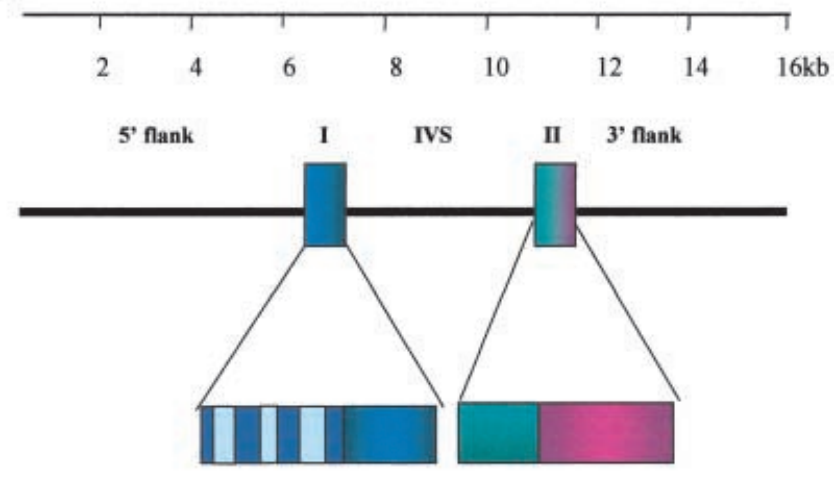

B.

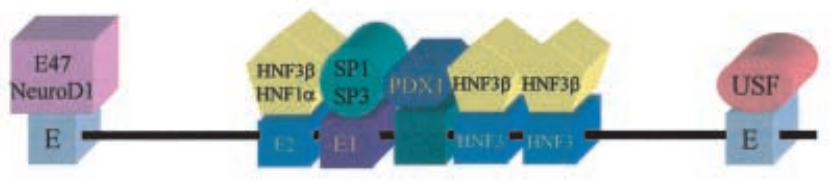

\begin{tabular}{cccccccc}
\hline & 1 & 1 & 1 & 1 & 1 \\
$-6 \mathrm{~kb}$ & $-5 \mathrm{~kb}$ & $-4 \mathrm{~kb}$ & $-3 \mathrm{~kb}$ & $-2 \mathrm{~kb}$ & $-1 \mathrm{~kb}$ & +1
\end{tabular}

Fig. 2 (A, B). Structure of the PDX1 and upstream regulatory region. A Schematic showing the structure of the PDX1 gene which contains two exons and one intron. Exon 1 encodes $\mathrm{NH}_{2}$-terminal sequences up to the homeodomain while exon 2 encodes the homeodomain and $\mathrm{COOH}$-terminal sequences. B Arrangement of regulatory sequences within the upstream regulatory region of $\mathrm{PDX} 1$

supported by experiments in which PDX-1 transfected into pancreatic $\alpha$ cells, which lack endogenous PDX-1 but contain islet-enriched factors, can stimulate the activity of an exogenous insulin promoter but not when transfected into fibroblasts which lack these additional factors [29]. Moreover, in acinar cell lines which exhibit endocrine and exocrine properties, the endogenous PDX-1 forms a trimeric complex with two TALE class homeodomain proteins PBX1b and MRG1 to activate the elastase promoter [34]. PBX1b and MRG1 are not expressed in beta cells and so the elastase promoter is not activated in these lines. This subtle interplay between PDX-1 and other factors in regulating promoter activity has been most extensively documented for the insulin gene.

In the insulin gene promoter, functional PDX-1 DNA-binding sites are arranged in close proximity to $\mathrm{E}$ boxes that bind a heterodimeric complex of the ubiquitously expressed bHLH protein E47 (also know as Pan-1) and its neuroendocrine specific bHLH partner NeuroD1. A boxes and E boxes interact synergistically to regulate transcription [35]. This minienhancer activity is dependent on interactions between all three proteins (PDX-1, E47 and NeuroD1) [36-38], although other ubiquitously expressed bHLH proteins could substitute for E47 [39]. The homeodomain of PDX-1 plays an important part in the assembly of this complex through protein-to-protein interactions with E47, NeuroD1 and the high mobility group protein (HMG1Y) [38]. HMG1Y is an architectural protein that affects the conformation of DNA and is important in the assembly of nuclear pore complexes. The interactions of PDX-1 with HMG1Y could explain how PDX-1 mediates its effects on the curvature of the DNA [40]. The effect this complex has on transcription is probably mediated through the clustering of multiple activation domains (within the different transcription factors) that could interact with potential coactivators (such as $\mathrm{CBP} / \mathrm{p} 300$ [41]) and directly with the preinitiation complex that assembles at the transcription start site.

Of interest, other homeodomain proteins such as the LIM domain protein $\mathrm{Lm} \times 1.1$ can also activate the $\mathrm{A} / \mathrm{E}$ minienhancer in co-operation with E47 [38]. As noted previously [38] the ability of other homeodomain factors in the beta cell (of which there are many [42]) to substitute for the overall function of PDX-1 in the formation of this activation complex on the insulin promoter could explain the observation that beta cells continue to express insulin when PDX1 is removed by Cre-mediated deletion of the PDX-1 gene [43]. This redundancy could also explain the relatively high amounts of insulin in human NES2Y beta cells that lack PDX-1 [44]. It could also explain the sustained concentrations of insulin when PDX-1 expression are reduced in beta cells by using an antisense RNA approach [45] and the presence of insulin in beta cells of the sand rat Psamonys obeseus, which in adult animals lack PDX-1 [46]. Moreover, overexpression of PDX-1 can repress insulin promoter activity possibly by interfering through a squelching mechanism (binding to and limiting the availability of other factors) in the formation of this transcription complex $[17,47]$.

The somatostatin gene promoter contains two elements (UE-A and TSE1) located within the region -113 to -85 that function as a minienhancer. The activity of this minienhancer is dependent on a co-operative interaction between PDX-1 binding at the TSE1 element (an A box) and a heterodimeric complex composed of two homeodomain proteins, $\mathrm{Pb} \times 1$ (the same one that interacts with PDX-1 in acinar cell lines) and Prep1, binding at the UE-A site [48]. This transcriptional complex is in part stabilised through interactions between PDX-1 and PBX1 that involve a pentapeptide motif FPWMK that resides immediately upstream of the PDX-1 homeodomain [49].

\section{Regulation of the pdx-1 gene}

Regulation of PDX-1 gene expression is particularly complex, involving sequences up to $6 \mathrm{~kb}$ from the transcription start site (Fig.2). There is a proximal $\mathrm{E}$ box at around -104 that binds the ubiquitous 

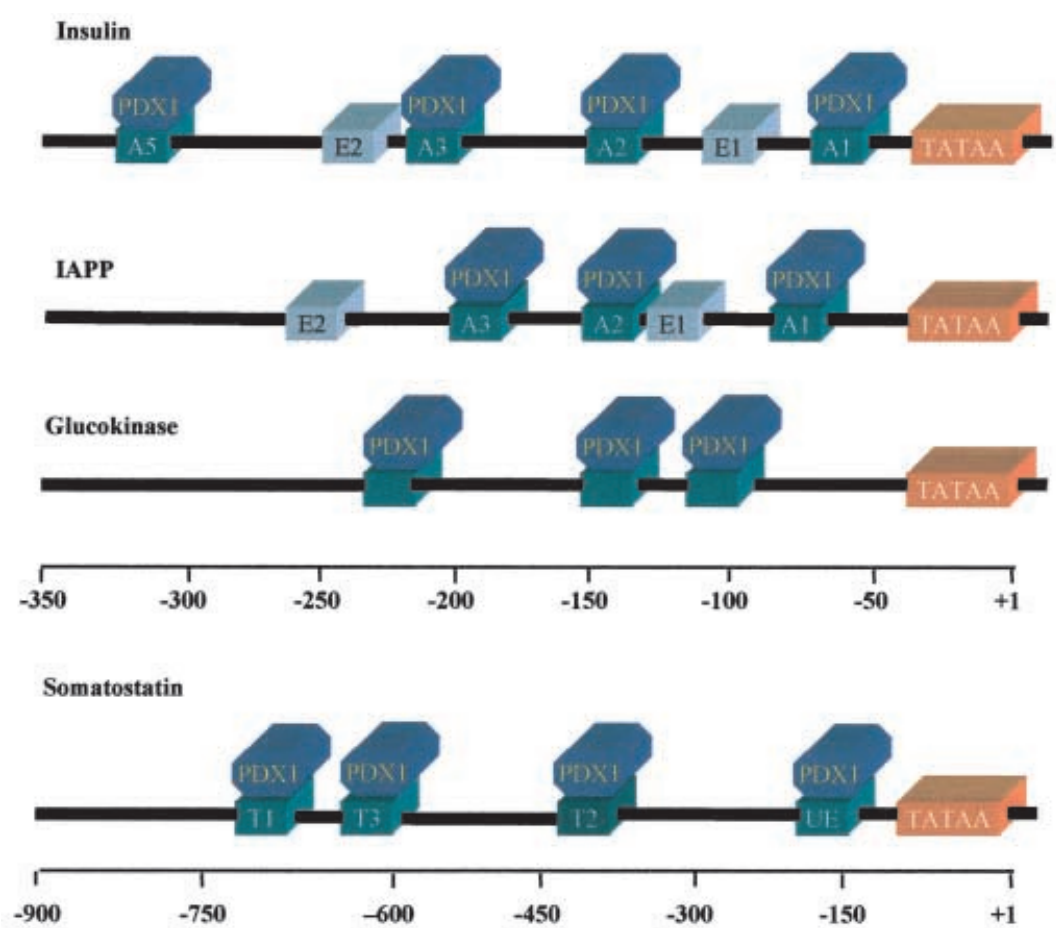

Fig.3. Arrangement of PDX1 binding sites within various gene regulatory regions. Schematic showing the arrangement of PDX1 in the human insulin, IAPP, glucokinase and somatostatin upstream regulatory regions. Care should be taken, in extrapolating functional relevance to the presence of PDX-1 binding sites. Consensus PDX-1 DNA-binding sites, i.e. $\mathrm{C}(\mathrm{C} /$ T)TAATG, are present in the promoters of a number of genes (including and in addition to those shown here) that are expressed in islets of Langerhans. Not all of these sites are functionally important as PDX-1, like most other homeodomain proteins, can bind with varying affinity to sequences containing the core TAAT motif

bHLH protein USF-1 $[50,51]$. In addition there are several sites that bind the forkhead winged-helix transcription factor $\mathrm{HNF} 3 \beta$ [33, 52-54]. Members of this family can open up chromatin to provide access to regulatory sequences. HNF3 $\beta$ could therefore prime the PDX-1 gene for expression by other transcription factors. PDX-1 itself binds at one of the HNF3 $\beta$ sites, which contains a TAAT core sequence, suggesting a possible autoregulatory feedback mechanism [33]. There is an additional $\mathrm{E}$ box at around $-6 \mathrm{~kb}$ that binds E47/NeuroD1 [53]. Other factors involved in regulating the PDX-1 gene include HNF1 $\alpha$ and SP1/3 [55]. Of note, glucocorticoids inhibit PDX-1 gene expression by interfering with $\mathrm{HNF} 3 \beta$ activity [53]. This suggests that the well-documented ability of glucocorticoids to inhibit cell maturation and insulin gene expression in foetal islets could in part reflect a block in PDX-1 gene expression.

\section{Nutrient and hormonal regulation of PDX-1}

It is well established that glucose and a number of other nutrients and some hormones regulate PDX-1 at several levels. The original studies aimed to identify factors that bound to sequences within the insulin promoter in a glucose-responsive manner [56, 57]. One such factor [16], later identified as PDX-1 [17], bound to sequences containing A boxes $[16,58]$. Glucose activation of PDX-1 DNA-binding activity occurred rapidly (within 10-15 min) and involved phosphorylation of the transcription factor. The effects of glucose could not be mimicked by cyclic AMP-increasing agents or tumour promoting phorbol esters, suggesting that neither cyclic AMP-dependent protein kinase $\mathrm{A}$ nor protein kinase $\mathrm{C}$ were involved [58].

Some of the mechanisms by which glucose stimulates PDX-1 DNA binding activity have since been shown [15] (Fig. 4). The signalling pathway involves phosphatidylinositol 3-kinase (PI 3-kinase) and a stress-activated protein kinase, $\mathrm{p} 38 / \mathrm{SAPK} 2$. The protein kinase p38/SAPK2 is a member of an expanding family of MAP kinase-related kinases that are activated in response to adverse stimuli such as heat, osmotic shock, ultraviolet light, DNA-damaging reagents and by proinflammatory cytokines that are produced under conditions of stress. A role for p38/ SAPK2 in mediating effects of glucose on PDX-1 DNA binding activity is supported by the following evidence: glucose effects are blocked by SB 203580 (a relatively specific inhibitor of p38/SAPK2), glucose stimulates the activity of MAPKAPK2 that lies downstream of $\mathrm{p} 38 / \mathrm{SAPK} 2$, glucose stimulates phos- 


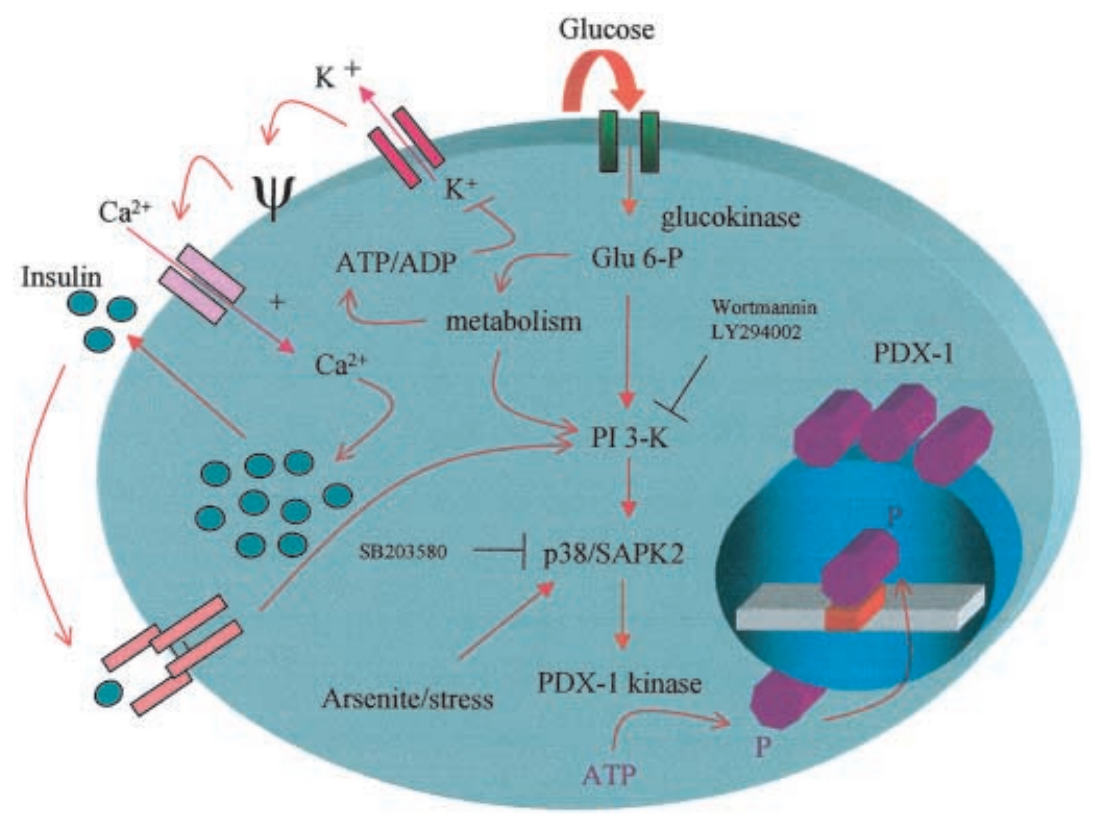

Fig.4. Model outlining the proposed regulation of PDX-1 by glucose and insulin. According to this model, glucose and insulin regulate PDX1 through p38/SAPK2 by a pathway that is inhibitable by wortmannin and LY294002, i. e. that involves PI 3kinase. PDX-1 can also be activated by arsenite and stress through p38/SAPK2 by a pathway that is unaffected by wortmannin or LY294002. It remains to be determined whether glucose effects on PDX-1 are dependent on a feedback effect of secreted insulin acting through insulin receptors on the surface of the beta cell or through metabolic intermediates that stimulate the PI 3-kinase pathway

phorylation of p38/SAPK2, arsenite (an activator of p38/SAPK2) mimics the effects of glucose, and overexpression of $\mathrm{p} 38 / \mathrm{SAPK} 2$ mimics the effects of glucose. Evidence supporting a role for PI 3-kinase includes inhibition of glucose-stimulated PDX-1 DNA-binding activity by inhibitors of PI 3-kinase such as wortmannin and LY294002 and by overexpression of a dominant negative form of PI 3-kinase (unpublished data). Additional signalling pathways could be involved, since atypical protein kinase $\mathrm{C}$ zeta $(\mathrm{PKC} \zeta)$ has also been implicated in glucosestimulated PDX-1 DNA-binding and transcriptional activity in MIN6 cells [59].

In beta cells, activation of the p38/SAPK 2 pathway by glucose involves PI 3-kinase, whereas activation by stress (e.g. treatment with sodium arsenite) is independent of PI 3-kinase. It is not clear how glucose activates PI 3-kinase. It could occur in part through a feedback effect of secreted insulin acting on insulin receptors on the beta cell [60], since exogenous insulin has also been shown to stimulate PDX-1 DNA binding activity [61]. Glucose metabolism leads to an increase in the ATP:ADP ratio resulting in closure of the ATP-dependent $\mathrm{K}^{+}$channel (Fig.4). The re- sultant membrane depolarisation activates voltage dependent calcium channels. The subsequent increase in cytosolic $\mathrm{Ca}^{2+}$ stimulates insulin secretion. It remains to be established if the effects of glucose are entirely dependent on secreted insulin or if metabolism can directly activate PI 3-kinase in beta cells.

Glucose stimulates the phosphorylation of PDX-1 $[29,62]$, although the phosphorylation sites have yet to be mapped and the kinases (a putative PDX-1 kinase) involved identified. Glucose also affects the intracellular distribution of PDX-1 [62, 63]. Under low glucose conditions PDX-1 can be localised by microscopy to the nuclear periphery. In high glucose PDX1 moves from the nuclear periphery to the nucleoplasm [63]. The translocation of PDX-1 to the nucleus could be mediated by nuclear localisation sequences located within helix 3 of the homeodomain $[64,65]$ (Fig.1). We have observed that PDX-1 shuttles between the nuclear periphery and the nucleoplasm in a phosphorylation dependent manner in response to changes in extracellular glucose and insulin concentrations [66]. The movement of PDX-1 from the nuclear periphery to the nucleoplasm when cells are stimulated with glucose or insulin is inhibited by wortmannin and SB 203580 suggesting that the PI 3kinase and p38/SAPK2 pathway is involved. Movement from the nucleoplasm to the nuclear periphery when cells are returned to non-stimulatory medium is inhibited by okadaic acid and calyculin A suggesting that intranuclear phosphatases are involved. In another study the movement of PDX-1 from the nuclear periphery to the nucleoplasm in response to glucose involved PI 3-kinase but not p38/SAPK2 [67], while in a further study no effect of glucose on the nuclear distribution of PDX-1 was observed [64]. These discrepancies can be explained possibly by method- 
ological differences in the use of endogenous or wild type recombinant PDX-1 compared with overexpressed chimaeric constructs in which PDX-1 sequences have been linked to enhanced green fluorescent protein (EGFP) or c-myc.

In addition to its effects on the phosphorylation of PDX-1, its DNA-binding activity and its distribution between the nuclear envelope and nucleoplasm, glucose also directly stimulates the trans-activation potential of the $\mathrm{NH}_{2}$-terminal activation domain by a mechanism that has yet to be established [68-70].

A number of hormones such as GLP-1 and TGF $\beta$ have effects on PDX-1 either at the level of DNAbinding activity, transactivation potential or expression of the PDX-1 gene [71-75]. GLP-1, which normally acts through a G-protein coupled receptor linked to protein Kinase A, was found to stimulate the activity of a construct containing the PDX-1 activation domain linked to the DNA-binding domain of Gal4. However, this PDX-1 activation domain lacked any phosphorylation sites for the cAMP-dependant kinase, protein kinase A [76], suggesting that the effects of GLP-1 on PDX-1 could be mediated by a cAMP-coupled p38/SAPK2 pathway [77]. It is possible that the response of PDX-1 to such extracellular signalling molecules (including insulin) could play a role in islet cell differentiation, maturation and neogenesis. It is likely that a wide range of growth factors and hormones that affect these processes will act at least in part through PDX-1.

This overview has focused on what is known about the nutrient and hormonal regulation of PDX-1 without reference to the relevance to target genes. This is because PDX-1 affects the transcription of numerous documented islet genes and possibly many more that have yet to be described. Its effects on each gene under particular conditions is dependent on a subtle interaction between transcription factors (positivelyacting and negatively-acting), which could also be activated or inactivated under similar conditions. It is therefore difficult to correlate specific effects on PDX-1 with more general multi-faceted effects on gene expression. An example of this is provided by glucose effects on the insulin gene promoter. Although the A box that binds PDX-1 is clearly involved, the overall effect is dependent on the interplay of a number of cis-acting elements that bind additional factors [78], and possibly coactivators that do not directly bind to DNA. Another example is provided by the differential effects of glucose on the insulin and IAPP promoter. The response of both promoters is dependent on PDX-1. In our observations activation of PDX-1 is insensitive to changes in intracellular calcium [79]. However, whereas activation of the insulin promoter in response to glucose is insensitive to calcium similar effects on the IAPP promoter are sensitive to calcium [80]. This indicates that additional calcium-sensitive factors are involved in the response of the IAPP but not the insulin promoter to glucose.

\section{PDX-1 and development of the pancreas}

PDX-1 plays an important role in the development of the pancreas. During embryogenesis the pancreas develops by fusion of a dorsal and ventral epithelial bud generated by evagination of the foregut [81]. In the mouse expression of PDX-1 is first detected in the embryo at day 8.5 (e8.5) in endoderm cells in the dorsal region of the gut. The molecular events underlying this restricted expression of PDX-1 are not clear. It seems to depend on the secretion of factors such as fibroblast growth factor 2 (FGF2) and activin $\beta$ B by the notocord [82], leading to the repression of the potent intracellular signalling molecules Sonic (shh) and Indian Hedgehog (ihh) in the dorsal region of the foregut destined to form the pancreas [83, 84]. This leads to the induction of the LIM domain transcription factor Isl-1 and in turn PDX-1 [85]. At e9.5 PDX-1 expression is localised to the dorsal and ventral buds, which appear concomitantly with glucagon expressing $\alpha$ cells. An additional factor, Hlxb9 is required for the development of the dorsal lobe [86, 87]. Insulin expressing cells are detected at e10.5, while somatostatin and PP producing cells appear later [88], although cell ablation studies with diphtheria toxin driven by various hormone regulatory sequences suggest that PP cells can appear much earlier [89]. There is a period during development when PDX-1 is expressed in cells of the pancreatic duct. It also appears in endocrine cells along with each islet hormone as well as in acinar cells with the exocrine enzyme amylase. Its distribution then becomes more restricted such that in the mature pancreas PDX-1 is localised in beta cells, $\delta$ cells and isolated cells of the pancreatic duct.

The importance of PDX-1 in these events is emphasised by gene knock-out experiments in transgenic mice. In mice in which the $p d x-1$ gene has been inactivated, the homozygotes $\left(\mathrm{pdx}-1^{-/-}\right)$have no pancreas, have abnormalities within specific regions of the duodenum, and die shortly after birth with highly increased urine glucose concentrations [90, 91]. Islet specific gene disruption of PDX-1, using a RIP-Cre (rat insulin promoter driving Cre-recombinase) conditional deletion approach, results in reduced beta cell mass and adult diabetes, a phenotype also characteristic of $p d x-1^{+/-}$mice [43]. These results emphasise the key role that PDX-1 plays as a major regulator of beta-cell identity and function.

Although we do not review the developmental biology of the pancreas in detail, it is important to understand that the role of PDX-1 should be viewed in the context of related events that occur in the developing pancreas. At around e14 the dorsal and ventral 
lobes fuse and a major wave of differentiation is initiated. During this phase the Notch signalling pathway controls the choice of cell fate [92]. Notch is a transmembrane receptor, Delta its transmembrane ligand and neurogenin-3 (ngn3) a bHLH protein that has two roles: firstly, to stimulate expression of Delta and secondly to drive cells towards an endocrine pathway by stimulating the expression of terminal differentiation genes such as NeuroD1. When activated by Delta expressed by a neighbouring cell, Notch triggers expression of another bHLH protein, Hes1, that inhibits expression of Ngn-3. This leads to a lateral inhibition model whereby activation of Ngn3 by extrinsic factors results in increased expression of Delta and NeuroD1 pushing the cell towards a differentiated endocrine cell lineage. The expressed Delta interacts with Notch on neighbouring cells leading to the activation of Hes-1, and inhibition of differentiation through its actions on ngn-3 [93]. Thus the cell that will differentiate inhibits its neighbouring cells such that it would then pursue a non-endocrine fate. In the differentiated cells NeuroD1 would lead to the expression of other factors such as the paired box proteins Pax- 4 and Pax- 6 and the homeodomain protein $\mathrm{Nk} \times 2.2$ that are vital for endocrine cell differentiation.

Taken collectively these data indicate that there are two waves of expression of PDX-1 in the developing pancreas. In the endoderm of the gut PDX1 defines a region that will form the pancreas. In the absence of PDX-1 the pancreatic buds will form but it is necessary for the growth of the buds. Ngn3 expression then defines an endocrine cell lineage, within which the homeodomain proteins PDX-1 (in a second wave) and Nkx6.1, along with the bHLH protein NeuroD1 act as beta-cell differentiation factors. This is relevant in understanding the role of PDX-1 in the renewal of islets that occurs after birth.

\section{PDX-1 and islet neogenesis}

During development, islet-like structures appear around e18.5. New islet formation continues for approximately the first three weeks of life, during which a mature morphology is adopted and glucose sensing activated. Thereafter, throughout the lifetime of the animal there is a constant slow turnover of islets [94]. Removal of ageing or damaged beta cells occurs through apoptosis, while the replacement of beta cells can occur either through replication of pre-existing beta cells or differentiation of latent progenitor cells (neogenesis) located within the pancreatic duct [95]. Under normal conditions the process of neogenesis is difficult to detect in adult rats [96], although in humans, single beta-cell units located in or along ductale structures can be detected at a reasonably high frequency ( $15 \%$ of all beta cells) [97].
The process of neogenesis is best studied in animal models where regeneration of the pancreas has been induced. These models include chemical destruction of beta cells by alloxan and streptozotocin, partial pancreatectomy, physical injury to the pancreas by ligation of the pancreatic duct or wrapping the pancreas in cellophane, or by overexpressing interferon $\gamma$ in the pancreas. In addition, in animal models with spontaneous diabetes, such as the NOD mouse, increased beta-cell neogenesis occurs in an attempt to compensate for the increased betacell death that causes diabetes. In most of these systems, including the NOD mouse [98], streptozotocin-treated rats [99], alloxan-treated mice [100], transgenic mice where interferon $\gamma$ is overexpressed in the pancreas [101], and in partially pancreatectomised rats [102], there is an increase in proliferation of isolated duct cells concomitant with expression of PDX-1. Accordingly, the process of neogenesis seems to recapitulate the early events in beta-cell development and lends support to the existence of a ductal stem cell population that contributes to betacell regeneration.

There is very little known about the source of these putative ductal stem cells or their regulation. A variety of locally produced growth factors as well as increased blood glucose concentrations have been implicated in regulating islet cell proliferation and differentiation [103]. It remains to be determined whether these factors have a direct effect on PDX-1. Certainly the phosphorylation pattern of PDX-1 within duct cells differs from that in differentiated beta cells [104] suggesting a differential response to extracellular signals. In addition, within duct cells PDX-1 could associate with other homeodomain proteins, such as PBX [105] or Msx-2 [106] to mediate duct cell specific responses.

\section{IPF-1 mutations in Type II diabetes}

The first indication that IPF-1 might be associated with Type II diabetes came from studies on a child in whom the pancreas did not develop (pancreatic agenesis) [107]. After replacement with insulin and pancreatic enzymes the female infant recovered well. The child was found to be homozygous for an inactivating cytosine deletion in the protein coding sequence of IPF-1 (pro63fsdelc). This frameshift mutation generated a truncated protein that lacked a functional homeodomain necessary for DNA binding and nuclear localisation. Members of the family that were heterozygote carriers of the mutant allele exhibited an autosomal dominant early onset form of Type II diabetes (MODY) [108, 109]. This brings to date five genes that have been associated with MODY, namely hepatocyte nuclear factor $4 \alpha$ (MODY1), glucokinase (MODY2), hepatocyte nuclear factor $1 \alpha$ (MODY3), 


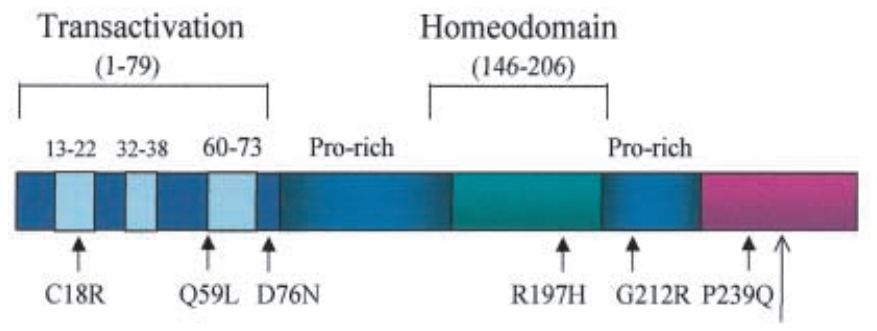

Pro243InsCCG

Fig. 5. PDX-1 mutations in Type II diabetes. Schematic showing mutations in PDX1 that have been identified in patients with late onset and early onset Type II diabetes

IPF-1 (MODY4) and hepatocyte nuclear factor $1 \beta$ (MODY5).

Additional IPF-1 mutations have since been identified in French [110], UK [111], and Swedish [112] families with both late-onset and early-onset Type II diabetes (Fig.5). Six of these were missense mutations, C18R, Q59L, D76N, R197H, G212R and $P 239 Q$ and one which inserts a proline at position 243. All mutations seem to affect transcription of the insulin gene with an impaired response to oral glucose.

The pro63fsdelc mutation is of particular interest since it could generate two isoforms of the protein [113]. One isoform, which could be detected with a $\mathrm{NH}_{2}$-terminal directed antibody (mut IPF-1 N) was present in the cytosol, contained an intact $\mathrm{NH}_{2}$-terminal transactivation domain (ORF-1) and a foreign 59 amino acid segment (ORF-2). This protein was unable to activate transcription of the insulin promoter and acted as a dominant negative by inhibiting the transactivation function of the wild-type IPF-1. The second mutant IPF-1 isoform was recognised by a $\mathrm{COOH}$-terminal antibody but not by a $\mathrm{NH}_{2}$-terminal directed antibody. This used an internal out of frame initiation codon to generate a third open reading frame (ORF-3). This open reading frame crosses over to the wild-type reading frame at the site of the cytosine deletion, generating a protein that contains the DNA binding domain and the nuclear localisation signal but no transactivation domain. These data indicate that IPF-1 mutations in Type II diabetes could act through dominant negative effects on the transcription of the insulin and other beta-cell genes that are regulated by IPF-1.

\section{Conclusions}

This review has described the discovery of PDX-1 and emphasised its importance as a major regulator of beta-cell identity and function. PDX-1 could have important implications for the aetiology and treatment of Type I and Type II diabetes. These include: (a) PDX-1 is the first gene to be associated with early-onset and late-onset forms of Type II diabetes. A better understanding of how mutations in the gene affect beta-cell function could provide important insights into beta-cell defects that contribute to the development of Type II diabetes and to the identification of additional candidate genes.

(aa) Studies on the mechanisms whereby nutrients and hormones control PDX- 1 have shown that PDX-1 expression is impaired in animal models of diabetes $[114,115]$ and in cell culture models of betacell glucotoxicity [116]. In addition, increased concentrations of fatty acid also decrease the expression of PDX-1 [117]. Collectively these results suggest that PDX-1 expression and/or activity could be impaired as a consequence of the prolonged hyperglycaemia or increased lipid concentrations that are associated with Type II diabetes and could therefore act as a therapeutic target. Such pharmacological agents could be directed at the signalling pathway controlling PDX-1.

(aaa) The data suggesting that PDX-1 could contribute to the regulation of beta-cell neogenesis has potential implications for the treatment of Type II diabetes. As reviewed previously [95], beta-cell mass is dynamic and regulated to maintain euglycaemia. Type II diabetes could result from a defect in the ability to compensate for the increased insulin demand by increasing beta-cell mass [95]. A better understanding of how PDX-1 contributes to beta-cell neogenesis could provide insights into how these compensatory mechanisms fail in Type II diabetes and identify new drugs or agents (e.g. growth factors) that can increase neogenesis. In this respect it is noticeable that GLP-1 (and its agonists) can stimulate PDX-1 expression and the rate of cell proliferation in duct cells $[74,77]$.

(ac) PDX-1 could be valuable in expanding beta-cell cultures to provide insulin-secreting cells for transplantation for the treatment of Type I diabetes. Thus progress has been made in expanding in culture ductal tissue derived from human pancreases in such a way that they can be directed to differentiate into glucose-responsive islet tissue [118]. Other studies have shown that PDX-1-positive adult islet cells can be expanded under defined culture conditions [119]. PDX1 has also been used to induce a more differentiated phenotype when transfected into human islet-derived cell lines [120].

(c) The fact that PDX-1 is a regulator of islet stem cell activity during embryogenesis and in adults has important implications. Recent studies have shown that stem cells derived from a number of sources can differentiate into a range of mature cell types distinct from those originally thought to be derived from the cells. This plasticity is reflected to some extent in the ability of acinar cells to transdifferentiate in culture into islet cells [121, 122]. A further example is provid- 
ed by the ability of nestin (a neuronal phenotypic maker)-positive cells, which have an extended proliferative potential in culture, to differentiate into pancreatic endocrine, exocrine and hepatic cells [123]. In addition, recent data show that adenovirus-mediated uptake of PDX-1 into liver stem cells in vivo can induce a beta cell-like phenotype that produces sufficient biologically active insulin to alleviate the hyperglycaemia associated with experimentally induced diabetes in rats [124].

Sources. Medline and a PubMed were searched for publications in the English language containing the words: "PDX-1/IDX-1/IPF-1, STF-1", "homeodomain proteins", "somatostatin", "glucokinase", "GLUT2", "IAPP" either alone or in conjunction with each other and in conjunction with "diabetes".

\section{References}

1. Karlsson O, Edlund T, Moss JB, Rutter WJ, Walker MD (1987) A mutational analysis of the insulin gene transcription control region: expression in beta cells is dependent on two related sequences within the enhancer. Proc Natl Acad Sci USA 84: 8819-8823

2. German M, Ashcroft S, Docherty K et al. (1995) The insulin gene promoter. A simplified nomenclature. Diabetes 44: 1002-1004

3. Ohlsson H, Karlsson O, Edlund T (1988) A beta-cell-specific protein binds to the two major regulatory sequences of the insulin gene enhancer. Proc Natl Acad Sci USA 85: 4228-4231

4. Naya FJ, Stellrecht CM, Tsai MJ (1995) Tissue-specific regulation of the insulin gene by a novel basic helix-loop-helix transcription factor. Genes Dev 9: 1009-1019

5. Lee JE, Hollenberg SM, Snider L, Turner DL, Lipnick N, Weintraub H (1995) Conversion of Xenopus ectoderm into neurons by NeuroD, a basic helix- loop-helix protein. Science 268: 836-844

6. Boam DS, Docherty K (1989) A tissue-specific nuclear factor binds to multiple sites in the human insulin-gene enhancer. Biochem J 264: 233-239

7. Karlsson O, Walker MD, Rutter WJ, Edlund T (1989) Individual protein-binding domains of the insulin gene enhancer positively activate beta-cell-specific transcription. Mol Cell Biol 9: 823-827

8. Boam DS, Clark AR, Docherty K (1990) Positive and negative regulation of the human insulin gene by multiple trans-acting factors. J Biol Chem 265: 8285-8296

9. Scott V, Clark AR, Hutton JC, Docherty K (1991)Two proteins act as the IUF1 insulin gene enhancer binding factor. FEBS Lett 290: 27-30

10. Ohlsson H, Thor S, Edlund T (1991) Novel insulin promoter- and enhancer-binding proteins that discriminate between pancreatic alpha- and beta-cells. Mol Endocrinol 5: 897-904

11. Ohlsson H, Karlsson K, Edlund T (1993) IPF1, a homeodomain-containing transactivator of the insulin gene. EMBO J 12: 4251-4259

12. Wright CVE, Schnegelsberg P, de Robertis EM (1988) Xlhox 8 a novel Xenopus homeoprotein restricted to a narrow band of endoderm. Development 104: 787-794
13. Leonard J, Peers B, Johnson T, Ferreri K, Lee S, Montminy MR (1993) Characterization of somatostatin transactivating factor-1, a novel homeobox factor that stimulates somatostatin expression in pancreatic islet cells. Mol Endocrinol 7: 1275-1283

14. Miller CP, McGehee RE Jr, Habener JF (1994) IDX-1: a new homeodomain transcription factor expressed in rat pancreatic islets and duodenum that transactivates the somatostatin gene. EMBO J 13: 1145-1156

15. Macfarlane WM, Smith SB, James RF et al. (1997) The p38/reactivating kinase mitogen-activated protein kinase cascade mediates the activation of the transcription factor insulin upstream factor 1 and insulin gene transcription by high glucose in pancreatic beta-cells. J Biol Chem 272: 20936-20944

16. Melloul D, Ben Neriah Y, Cerasi E (1993) Glucose modulates the binding of an islet-specific factor to a conserved sequence within the rat I and the human insulin promoters. Proc Natl Acad Sci USA 90: 3865-3869

17. Marshak S, Totary H, Cerasi E, Melloul D (1996) Purification of the beta-cell glucose-sensitive factor that transactivates the insulin gene differentially in normal and transformed islet cells. Proc Natl Acad Sci USA 93: 15057-15062

18. Peshavaria M, Gamer L, Henderson E, Teitelman G, Wright CV, Stein R (1994) XIHbox 8, an endoderm-specific Xenopus homeodomain protein, is closely related to a mammalian insulin gene transcription factor. Mol Endocrinol 8: 806-816

19. Perez-Villamil B, Schwartz PT, Vallejo M (1999) The pancreatic homeodomain transcription factor IDX1/IPF1 is expressed in neural cells during brain development. Endocrinology 140: 3857-3860

20. Lu M, Miller C, Habener JF (1996) Functional regions of the homeodomain protein IDX-1 required for transactivation of the rat somatostatin gene. Endocrinology 137: 2959-2967

21. Peshavaria M, Henderson E, Sharma A, Wright CV, Stein R (1997) Functional characterization of the transactivation properties of the PDX-1 homeodomain protein. Mol Cell Biol 17: 3987-3996

22. Inoue H, Riggs AC, Tanizawa Y et al. (1996) Isolation, characterization, and chromosomal mapping of the human insulin promoter factor 1 (IPF-1) gene. Diabetes 45 : 789-794

23. Stoffel M, Stein R, Wright CV et al. (1995) Localization of human homeodomain transcription factor insulin promoter factor 1 (IPF1) to chromosome band 13q12.1. Genomics 28 : $125-126$

24. Fiedorek FT Jr, Kay ES (1995) Mapping of the insulin promoter factor 1 gene (Ipf1) to distal mouse chromosome 5. Genomics 28: 581-584

25. Yokoi N, Serikawa T, Walther R (1997) Pd $\times 1$, a homeodomain transcription factor required for pancreas development, maps to rat chromosome 12. Exp Anim 46: 323-324

26. Milewski WM, Duguay SJ, Chan SJ, Steiner DF (1998) Conservation of PDX-1 structure, function, and expression in zebrafish. Endocrinology 139: 1440-1449

27. Waeber G, Thompson N, Nicod P, Bonny C (1996) Transcriptional activation of the GLUT2 gene by the IPF-1/ STF-1/IDX-1 homeobox factor. Mol Endocrinol 10: 1327-1334

28. Watada H, Kajimoto Y, Umayahara Y et al. (1996) The human glucokinase gene beta-cell-type promoter: an essential role of insulin promoter factor $1 / \mathrm{PDX}-1$ in its activation in HIT-T15 cells. Diabetes 45: 1478-1488

29. Serup P, Jensen J, Andersen FG et al. (1996) Induction of insulin and islet amyloid polypeptide production in pan- 
creatic islet glucagonoma cells by insulin promoter factor 1. Proc Natl Acad Sci USA 93: 9015-9020

30. Carty MD, Lillquist JS, Peshavaria M, Stein R, Soeller WC (1997) Identification of cis- and trans-active factors regulating human islet amyloid polypeptide gene expression in pancreatic beta-cells. J Biol Chem 272: 11986-11993

31. Bretherton-Watt D, Gore N, Boam DS (1996) Insulin upstream factor 1 and a novel ubiquitous factor bind to the human islet amyloid polypeptide/amylin gene promoter. Biochem J 313: 495-502

32. Schwartz PT, Perez-Villamil B, Rivera A, Moratalla R, Vallejo M (2000) Pancreatic homeodomain transcription factor IDX1/IPF1 expressed in developing brain regulates somatostatin gene transcription in embryonic neural cells. J Biol Chem 275: 19106-19114

33. Marshak S, Benshushan E, Shoshkes M, Havin L, Cerasi E, Melloul D (2000) Functional conservation of regulatory elements in the pdx-1 gene: PDX-1 and hepatocyte nuclear factor $3 \beta$ transcription factors mediate beta- cellspecific expression. Mol Cell Biol 20: 7583-7590

34. Swift GH, Liu Y, Rose SD et al. (1998) An endocrine-exocrine switch in the activity of the pancreatic homeodomain protein PDX1 through formation of a trimeric complex with PBX1 b and MRG1 (MEIS2). Mol Cell Biol 18: 5109-5120

35. German MS, Moss LG, Wang J, Rutter WJ (1992) The insulin and islet amyloid polypeptide genes contain similar cell- specific promoter elements that bind identical betacell nuclear complexes. Mol Cell Biol 12: 1777-1788

36. Peers B, Leonard J, Sharma S, Teitelman G, Montminy MR (1994) Insulin expression in pancreatic islet cells relies on cooperative interactions between the helix loop helix factor E47 and the homeobox factor STF-1. Mol Endocrinol 8: 1798-1806

37. Glick E, Leshkowitz D, Walker MD (2000) Transcription factor BETA2 acts cooperatively with E2A and PDX1 to activate the insulin gene promoter. J Biol Chem 275: 2199-2204

38. Ohneda K, Mirmira RG, Wang J, Johnson JD, German MS (2000) The homeodomain of PDX-1 mediates multiple protein-protein interactions in the formation of a transcriptional activation complex on the insulin promoter. Mol Cell Biol 20: 900-911

39. Itkin-Ansari P, Bain G, Beattie GM, Murre C, Hayek A, Levine F (1996) E2A gene products are not required for insulin gene expression: Endocrinology 137: 3540-3543

40. Read ML, Critchley L, Docherty K (1996) Mapping nutrient regulatory sequences in the insulin gene. Biochem Soc Trans 24: 240

41. Sharma A, Moore M, Marcora E et al. (1999) The NeuroD1/BETA2 sequences essential for insulin gene transcription colocalize with those necessary for neurogenesis and p300/CREB binding protein binding. Mol Cell Biol 19: 704-713

42. Rudnik A, Ling TY, Odagiri H, Rutter WJ, German MS (1994) Pancreatic $\beta$ cells express a diverse set of homeobox genes. Proc Natl Acad Sci USA 91: 12203-12207

43. Ahlgren U, Jonsson J, Jonsson L, Simu K, Edlund H (1998) Beta-cell-specific inactivation of the mouse Ipf1/ Pdx-1 gene results in loss of the beta-cell phenotype and maturity onset diabetes. Genes and Dev 12: 1763-1768

44. Macfarlane WM, Cragg H, Docherty HM et al. (1997) Impaired expression of transcription factor IUF1 in a pancreatic beta-cell line derived from a patient with persistent hyperinsulinaemic hypoglycaemia of infancy (nesidioblastosis). FEBS Lett 413: 304-308
45. Kajimoto Y, Watada H, Matsuoka Tet al. (1997) Suppression of transcription factor PDX-1/IPF1/STF-1/IDX-1 causes no decrease in insulin mRNA in MIN6 cells. J Clin Invest 100: 1840-1846

46. Leibowitz G, Melloul D, Yuli M et al. (2001) Defective glucose-regulated insulin gene expression associated with PDX- 1 deficiency in the Psammomys obesus model of type 2 diabetes. 3. Diabetes [50 Suppl 1]:S138-S139

47. Seijffers R, Ben David O, Cohen Y et al. (1999) Increase in PDX-1 levels suppresses insulin gene expression in RIN 1046-38 cells. Endocrinology 140: 3311-3317

48. Goudet G, Delhalle S, Biemar F, Martial JA, Peers B (1999) Functional and cooperative interactions between the homeodomain PDX1, Pbx, and Prep1 factors on the somatostatin promoter. J Biol Chem 274: 4067-4073

49. Peers B, Sharma S, Johnson T, Kamps M, Montminy M (1995) The pancreatic islet factor STF-1 binds cooperatively with $\mathrm{Pbx}$ to a regulatory element in the somatostatin promoter: importance of the FPWMK motif and of the homeodomain. Mol Cell Biol 15: 7091-7097

50. Sharma S, Leonard J, Lee S, Chapman HD, Leiter EH, Montminy MR (1996) Pancreatic islet expression of the homeobox factor STF-1 relies on an E- box motif that binds USF. J Biol Chem 271: 2294-2299

51. Qian J, Kaytor EN, Towle HC, Olson LK (1999) Upstream stimulatory factor regulates $\mathrm{Pdx}-1$ gene expression in differentiated pancreatic beta-cells. Biochem J 341: 315-322

52. Wu KL, Gannon M, Peshavaria M et al. (1997) Hepatocyte nuclear factor $3 \beta$ is involved in pancreatic $\beta$ cell specific expression of the $p d \times 1$ gene. Mol Cell Biol 17: 6002-6013

53. Sharma S, Jhala US, Johnson T, Ferreri K, Leonard J, Montminy M (1997) Hormonal regulation of an islet-specific enhancer in the pancreatic homeobox gene STF-1. Mol Cell Biol 17: 2598-2604

54. Gerrish K, Gannon M, Shih D et al. (2000) Pancreatic beta cell-specific transcription of the pdx-1 gene. The role of conserved upstream control regions and their hepatic nuclear factor $3 \beta$ sites. J Biol Chem 275: 3485-3492

55. Etti BS, Marshak S, Shoshkes M, Cerasi E, Melloul D (2001) A pancreatic $\beta$-cell-specific enhancer in the human Pdx-1 gene is regulated by HNF- $3 \beta$, HNF-1 $\alpha$ and SPs transcription factors. J Biol Chem 276: 17533-17540

56. German MS, Moss LG, Rutter WJ (1990) Regulation of insulin gene expression by glucose and calcium in transfected primary islet cultures. J Biol Chem 265: 22063-22066

57. Goodison S, Kenna S, Ashcroft SJ (1992) Control of insulin gene expression by glucose. Biochem J 285: 563-568

58. Macfarlane WM, Read ML, Gilligan M, Bujalska I, Docherty, K (1994) Glucose modulates the binding activity of the beta-cell transcription factor IUF1 in a phosphorylation-dependent manner. Biochem J 303: 625-631

59. Furukawa N, Shirotani T, Araki E et al. (1999) Possible involvement of atypical protein kinase $\mathrm{C}(\mathrm{PKC} \xi)$ in glucose- sensitive expression of the human insulin gene: DNA-binding activity and transcriptional activity of pancreatic and duodenal homeobox gene-1 (PDX-1) are enhanced via calphostin $\mathrm{C}$-sensitive but phorbol 12- myristate 13-acetate (PMA) and Go 6976-insensitive pathway. Endocr J 46: 43-58

60. Leibiger IB, Leibiger B, Moede T, Berggren PO (1998) Exocytosis of insulin promotes insulin gene transcription via the insulin receptor/PI-3 kinase/p70 s6 kinase and CaM kinase pathways. Mol Cell 1: 933-938 
61. Wu H, Macfarlane WM, Tadayyon M, Arch JR, James RF, Docherty K (1999) Insulin stimulates pancreaticduodenal homoeobox factor-1 (PDX1) DNA-binding activity and insulin promoter activity in pancreatic beta cells. Biochem J 344: 813-818

62. Macfarlane WM, McKinnon CM, Felton-Edkins ZA, Cragg H, James RF, Docherty K (1999) Glucose stimulates translocation of the homeodomain transcription factor PDX1 from the cytoplasm to the nucleus in pancreatic beta-cells. J Biol Chem 274: 1011-1016

63. Rafiq I, Kennedy HJ, Rutter GA (1998) Glucose-dependent translocation of insulin promoter factor-1 (IPF-1) between the nuclear periphery and the nucleoplasm of single MIN6 beta-cells. J Biol Chem 273: 23241-23247

64. Moede T, Leibiger B, Pour HG, Berggren P, Leibiger IB (1999) Identification of a nuclear localization signal, RRMKWKK, in the homeodomain transcription factor PDX-1. FEBS Lett 461: 229-234

65. Hessabi B, Ziegler P, Schmidt I, Hessabi C, Walther R (1999) The nuclear localization signal (NLS) of PDX-1 is part of the homeodomain and represents a novel type of NLS. Eur J Biochem 263: 170-177

66. Elrick LJ, Docherty K (2001) Phosphorylation dependent intranuclear shuttling of PDX-1 in pancreatic $\beta$ cells. Diabetes (in press)

67. Rafiq I, da Silva X, Hooper S, Rutter GA (2000) Glucosestimulated preproinsulin gene expression and nuclear trans- location of pancreatic duodenum homeobox-1 require activation of phosphatidylinositol 3-kinase but not p38 MAPK/SAPK2 J Biol Chem 275: 15977-15984

68. Petersen HV, Peshavaria M, Pedersen AA et al. (1998) Glucose stimulates the activation domain potential of the PDX-1 homeodomain transcription factor. FEBS Lett 431: $362-366$

69. Shushan EB, Cerasi E, Melloul D (1999) Regulation of the insulin gene by glucose: stimulation of trans-activation potency of human PDX-1 N-terminal domain. DNA Cell Biol 18: 471-479

70. Peshavaria M, Cissell MA, Henderson E, Petersen HV, Stein R (2000) The PDX-1 activation domain provides specific functions necessary for transcriptional stimulation in pancreatic beta-cells. Mol Endocrinol 14: 1907-1917

71. Buteau J, Roduit R, Susini S, Prentki M (1999) Glucagonlike peptide-1 promotes DNA synthesis, activates phosphatidylinositol 3-kinase and increases transcription factor pancreatic and duodenal homeobox gene 1 (PDX-1) DNA binding activity in beta (INS-1)-cells. Diabetologia 42: $856-864$

72. Wang X, Cahill CM, Pineyro MA, Zhou J, Doyle ME, Egan JM (1999) Glucagon-like peptide-1 regulates the beta cell transcription factor, PDX-1, in insulinoma cells. Endocrinology 140: 4904-4907

73. Perfetti R, Zhou J, Doyle ME, Egan JM (2000) Glucagonlike peptide- 1 induces cell proliferation and pancreaticduodenum homeobox-1 expression and increases endocrine cell mass in the pancreas of old, glucose-intolerant rats. Endocrinology 141: 4600-4605

74. Stoffers DA, Kieffer TJ, Hussain MA et al. (2000) Insulinotropic glucagon-like peptide 1 agonists stimulate expression of homeodomain protein IDX-1 and increase islet size in mouse pancreas. Diabetes 49: 741-748

75. Sayo Y, Hosokawa H, Imachi H et al. (2000) Transforming growth factor beta induction of insulin gene expression is mediated by pancreatic and duodenal homeobox gene-1 in rat insulinoma cells. Eur J Biochem 267: 971-978

76. Hussain MA, Habener JF (2000) Glucagon-like peptide 1 increases glucose-dependent activity of the homeoprotein
IDX-1 transactivating domain in pancreatic beta-cells. Biochem Biophys Res Commun 274: 616-619

77. Habener JH (2001) Glucagonlike peptide-1 agonist stimulation of Beta cell growth and development. Curr Opin Endocrinol Diabetes. 8: 74-81

78. German MS, Wang J (1994) The insulin gene contains multiple transcriptional elements that respond to glucose. Mol Cell Biol 14: 4067-4075

79. Macfarlane WM, Shepherd RM, Cosgrove KE, James RF, Dunne MJ, Docherty K (2000) Glucose modulation of insulin mRNA levels is dependent on transcription factor PDX-1 and occurs independently of changes in intracellular $\mathrm{Ca} 2+$. Diabetes 49: 418-423

80. Macfarlane WM, Campbell SC, Elrick LJ et al. (2000) Glucose regulates islet amyloid polypeptide gene transcription in a PDX1- and calcium- dependent manner. J Biol Chem 275: 15330-15335

81. Edlund H (1999) Pancreas: how to get there from the gut? Curr Opin Cell Biol 11: 663-668

82. Hart AW, Baeza N, Apelqvist A, Edlund H (2000) Attenuation of FGF signalling in mouse beta-cells leads to diabetes. Nature 408: 864-868

83. Hebrok M, Kim SK, Melton DA (1998) Notochord repression of endodermal Sonic hedgehog permits pancreas development. Genes Dev 12: 1705-1713

84. Kim SK, Melton, DA (1998) Pancreas development is promoted by cyclopamine, a hedgehog signaling inhibitor. Proc Natl Acad Sci USA 95: 13036-13041

85. Ahlgren U, Pfaff SL, Jessell TM, Edlund T, Edlund H (1997) Independent requirement for ISL1 in formation of pancreatic mesenchyme and islet cells. Nature 385: 257-260

86. Li H, Arber S, Jessell TM, Edlund H (1999) Selective agenesis of the dorsal pancreas in mice lacking homeobox gene Hlxb9. Nat Genet 23: 67-70

87. Harrison KA, Thaler J, Pfaff SL, Gu H, Kehrl JH (1999) Pancreas dorsal lobe agenesis and abnormal islets of Langerhans in Hlxb9-deficient mice. Nat Genet 23: 71-75

88. Sander M, German M (1997) The Beta cell transcription factors and development of the pancreas. J Mol Med 75: 327-340

89. Herrera PL, Huarte J, Zufferey R et al. (1994) Ablation of islet endocrine cells by targeted expression of hormone- promoter-driven toxigenes. Proc Natl Acad Sci USA 91: 12999-13003

90. Jonsson J, Carlsson L, Edlund T, Edlund H (1994) Insulinpromoter-factor 1 is required for pancreas development in mice. Nature 371: 606-609

91. Offield MF, Jetton TL, Labosky PA et al. (1996) PDX-1 is required for pancreatic outgrowth and differentiation of the rostral duodenum. Development 122: 983-995

92. Apelqvist A, Li H, Sommer L et al. (1999) Notch signalling controls pancreatic cell differentiation. Nature 400: 877-881

93. Jensen J, Pedersen EE, Galante P et al. (2000) Control of endodermal endocrine development by Hes-1. Nat Genet 24: $36-44$

94. Montanya E, Nacher V, Biarnes M, Soler J (2000) Linear correlation between beta-cell mass and body weight throughout the lifespan in Lewis rats: role of beta-cell hyperplasia and hypertrophy. Diabetes 49: 1341-1346

95. Bonner-Weir S (2000) Islet growth and development in the adult. J Mol Endocrinol 24: 297-302

96. Wang RN, Bouwens L, Kloppel,G (1994) Beta-cell proliferation in normal and streptozotocin-treated newborn rats: site, dynamics and capacity. Diabetologia 37: 1088-1096 
97. Bouwens L, Pipeleers DG (1998) Extra-insular beta cells associated with ductules are frequent in adult human pancreas. Diabetologia 41: 629-633

98. O'Reilly LA, Gu D, Sarvetnick N et al. (1997) alpha-Cell neogenesis in an animal model of IDDM. Diabetes 46: 599-606

99. Fernandes A, King LC, Guz Y, Stein R, Wright CV, Teitelman G (1997) Differentiation of new insulin-producing cells is induced by injury in adult pancreatic islets. Endocrinology 138: 1750-1762

100. Waguri M, Yamamoto K, Miyagawa JI et al. (1997) Demonstration of two different processes of beta-cell regeneration in a new diabetic mouse model induced by selective perfusion of alloxan. Diabetes 46: 1281-1290

101. Kritzik MR, Krahl T, Good A et al. (2000) Transcription factor expression during pancreatic islet regeneration. Mol Cell Endocrinol 164: 99-107

102. Sharma A, Zangen DH, Reitz P et al. (1999) The homeodomain protein IDX-1 increases after an early burst of proliferation during pancreatic regeneration. Diabetes 48: $507-513$

103. Hellerstrom C, Swenne I (1985) Growth Pattern of pancreatic islets in animals. Volk BW, Arquilla ER (eds) The Diabetic Pancreas. 2nd Edn, Plenum Medical Press, New York, pp 64-69

104. Heimberg H, Bouwens L, Heremans Y, Van De CM, Lefebvre V, Pipeleers D (2000) Adult human pancreatic duct and islet cells exhibit similarities in expression and differences in phosphorylation and complex formation of the homeodomain protein Ipf-1. Diabetes 49: 571-579

105. Dutta S, Gannon M, Peers B, Wright C, Bonner-Weir S, Montminy M (2001) PDX:PBX complexes are required for normal proliferation of pancreatic cells during development. Proc Natl Acad Sci USA 98: 1065-1070

106. Kritzik MR, Jones E, Chen Z et al. (1999) PDX-1 and Msx-2 expression in the regenerating and developing pancreas. J Endocrinol 163: 523-530

107. Stoffers DA, Zinkin NT, Stanojevic V, Clarke WL, Habener JF (1997) Pancreatic agenesis attributable to a single nucleotide deletion in the human IPF1 gene coding sequence. Nat Genet 15: 106-110

108. Stoffers DA, Ferrer J, Clarke WL, Habener JF (1997) Early-onset type-II diabetes mellitus (MODY4) linked to IPF1. Nat Genet 17: 138-139

109. Clocquet AR, Egan JM, Stoffers DA et al. (2000) Impaired insulin secretion and increased insulin sensitivity in familial maturity-onset diabetes of the young 4 (insulin promoter factor 1 gene). Diabetes 49: 1856-1864

110. Hani EH, Stoffers DA, Chevre JC et al. (1999) Defective mutations in the insulin promoter factor-1 (IPF-1) gene in late-onset type 2 diabetes mellitus. J Clin Invest 104: R41-R48

111. Macfarlane WM, Frayling TM, Ellard S et al. (2000) Missense mutations in the insulin promoter factor-1 gene predispose to type 2 diabetes. J Clin Invest 106: 717
112. Weng J, Macfarlane WM, Lehto M et al. (2001) Functional consequences of mutations in the MODY4 gene (IPF1) and coexistence with MODY3 mutations. Diabetologia 44: 249-258

113. Stoffers DA, Stanojevic V, Habener JF (1998) Insulin promoter factor-1 gene mutation linked to early- onset type 2 diabetes mellitus directs expression of a dominant negative isoprotein. J Clin Invest 102: 232-241

114. Seufert J, Weir GC, Habener JF (1998) Differential expression of the insulin gene transcriptional repressor CCAAT/enhancer-binding protein beta and transactivator islet duodenum homeobox-1 in rat pancreatic beta cells during the development of diabetes mellitus. J Clin Invest 101: 2528-2539

115. Jonas JC, Sharma A, Hasenkamp W et al. (1999) Chronic hyperglycemia triggers loss of pancreatic beta cell differentiation in an animal model of diabetes. J Biol Chem 274: 14112-14121

116. Olson LK, Sharma A, Peshavaria M et al. (1995) Reduction of insulin gene transcription in HIT-T15 beta cells chronically exposed to a supraphysiologic glucose concentration is associated with loss of STF-1 transcription factor expression. Proc Natl Acad Sci USA 92: 9127-9131

117. Gremlich S, Bonny C, Waeber G, Thorens B (1997) Fatty acids decrease IDX-1 expression in rat pancreatic islets and reduce GLUT2, glucokinase, insulin, and somatostatin levels. J Biol Chem 272: 30261-30269

118. Bonner-Weir S, Taneja M, Weir GC et al. (2000) In vitro cultivation of human islets from expanded ductal tissue. Proc Natl Acad Sci USA 97: 7999-8004

119. Beattie GM, Itkin-Ansari P, Cirulli V et al. (1999) Sustained proliferation of PDX-1 + cells derived from human islets. Diabetes 48: 1013-1019

120. Itkin-Ansari P, Demeterco C, Bossie S et al. (2000) PDX-1 and cell-cell contact act in synergy to promote Delta-cell development in a human pancreatic endocrine precursor cell line. Mol Endocrinol 14: 814-822

121. Gmyr V, Kerr-Conte J, Belaich S et al. (2000) Adult human cytokeratin 19-positive cells reexpress insulin promoter factor 1 in vitro: further evidence for pluripotent pancreatic stem cells in humans. Diabetes 49: 1671-1680

122. Rooman I, Heremans Y, Heimberg H, Bouwens L (2000) Modulation of rat pancreatic acinoductal transdifferentiation and expression of PDX-1 in vitro. Diabetologia 43: 907-914

123. Zulewski H, Abraham EJ, Gerlach MJ et al. (2001) Multipotential nestin-positive stem cells isolated from adult pancreatic islets differentiate ex vivo into pancreatic endocrine, exocrine, and hepatic phenotypes. Diabetes 50: 521-533

124. Ferber S, Halkin A, Cohen H et al. (2000) Pancreatic and duodenal homeobox gene 1 induces expression of insulin genes in liver and ameliorates streptozotocin-induced hyperglycemia. Nat Med 6: 568-572 